\title{
LETTERS, NOVELS, AND IMPERIAL NOSTALGIA
}

\author{
Gayle Rogers \\ (Pittsburg University)
}

José Luis Venegas, Transatlantic Correspondence: Modernity,

Epistolarity, and Literature in Spain and Spanish America, 1898-

1992., Ohio, Ohio State University Press, 2014, 241+X pp.

ISBN: 978-0-8142-1256-1

The dualism encoded in both the English «letters» and the Spanish letras signals what has become a fruitful new direction in scholarship: the relationship between epistolarity and literatureespecially the institutions and grand traditions of literature. This relationship has prompted a host of studies and, more recently, websites such as the Republic of Letters and Six Degrees of Francis Bacon. Such work stands in opposition to the denigration or dismissal of epistolarity across decades of scholarship grounded in the elevation of form and aesthetic innovation, which usually prized genres and modes of writing such as novels, poems, and plays. Letters were interesting historical documents or pre-texts that lend insight into more famous works, but were private and often uncollected; whatever was meant to be public was published, even if published as letters, as in Juan Valera's Cartas americanas. The monuments of literary history told the epic fates of national, ethnic, or religious groups; they were addressed to vast, partially differentiated audiences, not to individuals. Letters were also marked by controversy: in 1975, for example, the publication of James Joyce's obscene and sexually explicit personal letters to his wife set off a firestorm of criticism grounded in claims that an author's private world has been violated - that letters were, by definition, a mode of writing never meant for public consumption. Furthermore, epistolarity was seen as primarily the domain of women, many of whom had no access to publication, and thus was understood as informal, underdeveloped, laden with debased sentiment and emotion, never reaching the aesthetic heights of the serious literary genres.

Picking up the revaluations of epistolarity brought about by New Historicism, archival and digital research, and studies in feminism and the history of literacy, scholars now have tied 
together the ways in which the worlds of private or semi-private letters and public texts were deeply entwined, indeed were inseparable. Thus, when Jürgen Habermas sought to explain the origins of our contemporary modernity and its public sphere in the Enlightenment, as manifested in England, France, and Germany, he named the eighteenth century the «century of the letter» (qtd. in Venegas 7). Critics such as John Beverley and Ángel Rama have shown the high degree of integration between the traditions of letras in the Spanish colonies and the administrative apparatuses by which colonialism operated in what Beverley deemed «philological states.» Working in this vein but modifying its orientation toward central Europe, José Luis Venegas's exciting monograph Translatlantic Correspondence locates critical and provocative formulations of modernity in the letters of key figures in Hispanophone writing between two signal years: 1898, when Spain lost its final New World possessions in a war with the upstart American empire, and 1992, the quadricentennial of Columbus's landfall in Hispaniola. For Venegas, Darío, Unamuno, Martín Gaite, and García Márquez were not only titanic figures in Spanish literature across the twenty-first century, they were also letter-writers who used correspondence to rearticulate and reconfigure what modernity might mean for Spain and Spanish America.

In fact, Venegas begins with a public campaign launched in 1894 by Senator Santiago de Liniers to promote letter-writing as a means to «renew an authentic national identity» in Spain and to rejuvenate the Castilian tongue, both of which were under threat of «invasion» (1). Francisco Silvela picked up this campaign as prime minister shortly thereafter, and within a few years, leading intellectuals, statesmen, diplomats, authors, and cultural figures were engaged in a protracted effort to foment a transatlantic pan-Hispanic union whose very map was limned by the international postal service. Altamira, Juderías, Costa, and Lafuente, many others agreed that «the solution to national decline during this historical period (after 1898) was not to be found in the sort of scientific and technological development dominant in materialistic Europe, but in the idealistic revitalization of Spain's imperial past and its civilizing mission» (51). The network or circuit that would animate this simultaneous backward- and forward-looking solution operated via epistolary exchange: letters were sincere, first-person, primary, even previous to fiction, and thus they embodied more organically the mystical «spirit» of the Spanish raza.

This intimate connection between letters and visions of empire-in this case, a fading empire and the designs to restructure it or to mourn it nostalgically that pervaded Spanish fiction 
in the twentieth century-is the focus of Venegas's study. Epistolary fiction in Spain was, Venegas notes, an «exotic plant»; the country had no native tradition of novels such as Richardson's Pamela or Goethe's Sorrows of Young Werther. (In reality, those texts too borrowed and transplanted from foreign traditions in their own work to domesticate and nativize a new mode of writing in their respective countries.) But in fact, Venegas suggests, we are better suited to dive back into the messiness of letters themselves before situating them within a dominant genre such as the novel. Letters thrived on «non-synchronicity and non-simultaneity, which complicate the modern idea of historical progress»; they contain gaps, «time lags,» «blank spaces and lacunae in the manuscript,» and more, beyond being ambiguously personal and possibly public at various moments (9). Their very lack of structure, plan, or rigor, in other words, is an opening for scholars to find in them not a putatively more authentic mode of expression - that would buy into a host of discredited conceptions of essence and race-but, as Venegas puts it, an incongruous and asymmetrical «stylistic manifestation of the symbolic partitions, borders, fractures, and hierarchies that determine Spain's and Spanish America's relationship to each other and to the master narrative of European modernity» (9).

This master narrative, of course, marginalized Spain as backwards and un-European, thus justifying the cultural and political domination of central Europe and its colonial projects while rationalizing Spain's imperial «failures» as the product of incompetent mismanagement. And — without reasserting Spain's exceptionalism—Venegas demonstrates that «from modernity's Hispanic periphery, literary epistolarity is, despite the borrowings from European epistolary models..., not a medium through which 'the individual unfolded himself in his subjectivity,'» as Habermas claimed, but was «a form that interrupts and deviates that process of unfolding» (216). Instead, he contends that «the letter expresses the double consciousness created by Spain's and Spanish America's uneven engagements with dominant narratives of modernity, on the one hand, and with their shared colonial experience, on the other hand» (216). And thus, the writers that Venegas treats are able «to simultaneously embrace and reject versions of the modern imposed from without» through a complex of letters and fiction (23). We therefore find Darío using letters, their metaphorical power, and the systems of exchange that they employ to stage his simultaneous rejection of Spain as metropole and embrace of the very pan-Hispanism that emanated from the academies in Madrid that he assaulted. 
Letters, it turns out, did not create the unified project of imperial spirit-building that Liniers and Silvela imagined; nor did they yield the kinds of secular public spheres that English, French, and German scholars have both idealized and critiqued in the past three decades. And yet, they left a vibrant record of partial connections, failures, and fissures that scholars working over a century later have yet to recover and explore fully. They are the sites where, Venegas shows, writers negotiated colonial difference, imperial legacies, national histories, and their own personal investments in all of these. Through the archives of an «imaginary postal system,» Venegas's sweeping and ambitious study reconstructs a world in which both correspondence (in all its sense) and difference actually «inspired cultural and literary creativity» (17). Indeed, one of the key contributions of Venegas's study is to recover the expansive and paradoxical, often surprising reach of a crucially common agreement that letters were the media through which such creativity and imagination should enter the material world.

Translatlantic Correspondence traces this hybrid fictional and actual world through a valuable genealogy of Spain's adapted epistolary writing since Caldalso, through a refreshing angle on the debates between Valera and Sarmiento, and on outward to the Gustavo Sainz, Ricardo Piglia, and Diamela Eltit, among many others. Unamuno is arguably the first major player for Venegas. The philosopher, novelist, and poet who diagnosed Spain with «epistolofobia» (55) believed that letter-writing was «the linchpin between a pre-modern Volkgeist and a modern social contract» that could «unearth a true Spanish essence» that unites all Spanish-speakers around the world (25). This last turn means that, at Venegas puts is, «epistolarity allows (Unamuno) to hide the discursive construction and colonial dimension of national and transatlantic 'imagined communities'» (52). With a sharp eye for metaphor and wordplay in Unamuno and without the sense of moral judgment or condemnation that taints much scholarship on the Basque figure, Venegas turns these internal contradictions into a vital new reading of exactly how and why Unamuno structured his notion of intrahistoria as he did.

With deft in his swerve, Venegas shifts to Mexico, where for Sainz, letters «create the sort of horizontal network structure that Mexico's reified state democracy can no longer provide as it represses civil society in its race toward First World status» (27). The 1968 student massacre had exposed Mexico, in Sainz's view, as a holdover totalitarian state from a previous era. In response, «epistolary exchange as a social practice is transformed into a radical strategy of resistance to 
state hegemony in Sainz's fiction,» Venegas claims in a series of acute readings (106). Pedro Salinas in exile then plays perhaps a surprising role in Venegas's study, given the writer's politics, but his role is telling and fruitful. He becomes an imperial apologist through epistolarity in his continual framing of the battle for the soul of the Americas as a battle of Robinson Crusoe (northern, Anglo-Saxon, materialistic, rational) against Don Quixote (southern, Iberian, spiritual, irrational). Letter-writing, Salinas holds, is a fully Quixotic endeavor, both in the literary and commonplace senses in English (83). A quixotic character himself, García Márquez appears in this web of connectivity too. His controversial and elusive presence at the 1992 Expo in Seville prompts Venegas to El amor en los tiempos del cólera and El general en su laberinto as «the fictional manifestations of his determined effort to prevent Spain and Europe from assimilating Latin American culture in the late twentieth century» through manipulating epistolarity (188).

There is much more detail in this fine monograph than one could include here: Venegas's research and his mastery of several fields of scholarship and criticism are consistently impressive. He notes, via José-Carlos Mainer, that «the erosion of collective frames of identity (national, ideological, religious) caused by market forces» led to a «reprivatización of literature after Franco's death» (126). The multiple senses of «privatization» here-from subjective interiority to the sale of publicly-held assets to individual citizens-bespeak the conflicts that epistolarity highlights for Venegas. This book weaves theories of subjectivity associated with Derrida together with accounts of sociality and public life from across the American left, among other sites. While Venegas restricts himself to Hispanophone letters, it is clear that the ramifications of his study go beyond that scholarly field. If most Anglo-American academics have tacitly adopted the public sphere model of German Marxists such as Habermas as an implicit historical norm, or at least as a central narrative of the development of modern structures of social interrelations, what might look different if they were to understand this Hispanophone example as another node on a flattened, decentralized plane rather than purely as a deviant variation? And, how do we preserve both the sense of Spain's and Spanish America's different histories and experiences in this realm without either reinscribing their exceptionalism or creating a new, unwritten norm through them? These questions will persist into the coming decades of scholarship on Hispanophone letters, and Venegas's book will be a crucial resource for tackling them. 